\title{
The Results of Surgical Treatment of Placenta Accreta in Women with a Previous Cesarean Delivery
}

\author{
Natalya N. Ignatieva, $\mathrm{PhD}^{1}$; Natalya I. Douglas, $\mathrm{PhD}, \mathrm{ScD}^{1 *}$; Tatyana N. Neustroeva ${ }^{2}$; \\ Dmitry D. Noev, $\mathrm{PhD}^{2}$; Danara D. Donskaya ${ }^{3}$; Maya P. Slobodchikova ${ }^{4}$ \\ ${ }^{I}$ M.K. Ammosov North-Eastern Federal University, Medical Institute, Yakutsk, Russia \\ ${ }^{2}$ Republican Hospital \#1(National health center) of the Republic of Sakha (Yakutia), Yakutsk, Russia \\ ${ }^{3}$ Yakutsk Republican Clinical Hospital, Yakutsk, Russia \\ ${ }^{4}$ St. Petersburg State Pediatric Medical University, St. Petersburg, Russia
}

\begin{abstract}
This article presents the results of surgical treatment of placenta accreta in 18 women with a previous cesarean delivery according to the data of the Departments of gynecology at the Yakutsk Republican Clinical Hospital and Republican Hospital \#1 (National health center) of the Republic of Sakha (Yakutia) for the period of 2018-2019. The diagnosis of placenta accreta spectrum (PAS) was based on ultrasound findings and MRI data. Seventeen patients underwent metroplasty. In PAS disorders, metroplasty is fertility-preserving surgery with minimal blood loss both by the laparotomic and laparoscopic approaches. (International Journal of Biomedicine. 2019;9(4):373-375.)
\end{abstract}

Key Words: placenta accreta spectrum $\bullet$ cesarean delivery scars $\bullet$ metroplasty $\bullet$ laparotomy $\bullet$ laparoscopy

\section{Introduction}

Placenta accreta is now the main cause of postpartum hemorrhage resulting in maternal and neonatal morbidity. Placenta accreta is often used as a general term but is defined by the levels of invasion of chorionic villi into maternal myometrium. In regard to terminology, recent guidelines suggested that placenta accreta spectrum (PAS) be used going forward. PAS includes (1) superficial placenta accreta (also called placenta creta, vera, or adherenta), where the villi attach directly to the surface of the myometrium without invading it; (2) placenta increta, where the villi penetrate deeply into the myometrium up to the external layer; and (3) placenta percreta, where the invasive villous tissue reaches and penetrates through the uterine serosa. ${ }^{(1)}$ Abnormal adherence of the placenta to the myometrium is established in very early pregnancy. The diagnosis of a PAS is made on the basis of histopathologic

*Corresponding author: Natalia I. Douglas PhD, ScD. Head of the Department of Obstetrics and gynecology of the M. K. Ammosov North-Eastern Federal University. Yakutsk, the Republic of Sakha (Yakutia), the Russian Federation. E-mail: nduglas@, yandex.ru examination and characterized by an absence of decidua, and chorionic villi are seen directly adjacent to myometrial fibers. Placenta accreta is the most common component of PAS and accounts for $75 \%$ of cases. Traditionally, PAS is thought to occur as a consequence of a localized uterine injury (e.g., previous cesarean section [PCS]), which can result in locally defective decidualization/scarring and abnormal placental adherence in a subsequent pregnancy. ${ }^{(2,3)}$ In the presence of a low-lying placenta (placenta previa) and 3 PCSs, a woman would have a $61 \%$ risk of PAS..$^{(4)}$

The development of PAS is a complex multifactorial process. Normal placentae do not proceed beyond the inner third of the myometrium. The underlying molecular mechanisms of invasive placentation are poorly understood; proposed hypotheses include a combination of primary absence of the decidua or basal plate, abnormal maternal vascular remodeling, and excessive extravillous trophoblastic invasion. ${ }^{(5)}$ Extensive neovascularization is clearly evident in the majority of PAS cases. The current prevailing hypothesis for explaining this pathology is that a defect of the endometrium-myometrial interface, typically at the site of a prior hysterotomy, leads to a failure of normal decidualization in the corresponding uterine area. This allows extravillous 
trophoblastic infiltration and villous tissue to develop deeply within the myometrium, including its circulation, and to sometimes reach the surrounding pelvic organs. ${ }^{(6,7)}$

Prenatal diagnosis of RAS is a key element to improving maternal and perinatal outcome. Standard transabdominal ultrasonography is a reliable tool for diagnosing invasive placentation and is the primary tool for the antenatal diagnosis of the morbidly adherent placenta. ${ }^{(8,9,10)}$ Warshak et al suggest a two stage protocol in evaluating a patient at risk for abnormal placentation using ultrasonography first, then MRI for cases that are inconclusive. ${ }^{(1)}$ Riteau et al showed that ultrasound remains the more sensitive imaging modality for diagnosing accreta and suggest that MRI be complementary to ultrasound, especially in cases where there are few ultrasound signs. ${ }^{(12)} \mathrm{A}$ number of potential serum biomarkers have been investigated in PAS. At present, a sensitive serum biomarker for invasive placentation remains elusive. ${ }^{(13,14)}$

The objective of this study was to identify a risk group of women with a previous cesarean delivery for PAS and find the optimum surgical way to preserve a reproductive function.

\section{Materials and Methods}

Based on the data of the Departments of gynecology at the Yakutsk Republican Clinical Hospital and Republican Hospital \#1 (National health center) of the Republic of Sakha (Yakutia) for the period of 2018-2019, a total of 18 PAS cases with the PCS were analyzed and the results of surgical treatment with different approaches were compared.

Group 1 included 10 women aged from 28 to 41 years (mean age of 34.5 years) with placenta accreta into the scar from the PCS who underwent laparotomic surgery. Group 2 included 8 women aged from 20 to 39 years (mean age of $29.5 y e a r s)$ with placenta accreta into the scar from the PCS who underwent laparoscopic surgery.

The diagnosis of PAS was based on ultrasound findings and MRI data. Pictures 1 and 2 show a thinned (up to $2 \mathrm{~mm}$ ) postoperative scar with a niche of $12 \times 10 \mathrm{~mm}$ in size. In the uterine cavity there is an embryo $(48 \times 26 \times 47 \mathrm{~mm}$ in size $)$; the chorionic villi are penetrating the postoperative scar. Pictures 3 and 4 show a thinned (up to $1.8 \mathrm{~mm}$ ) postoperative scar with a niche of $15 \times 12 \mathrm{~mm}$. The MRI revealed an embryo $(23 \times 14 \times 12 \mathrm{~mm}$ in size) lying close to the scar; the boundaries of the scar are blurred.

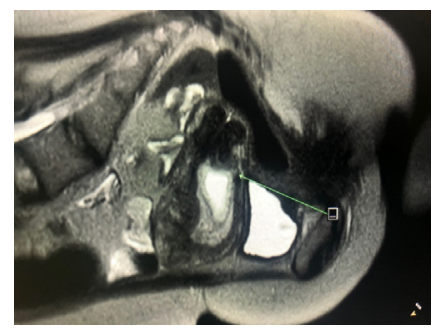

(1)

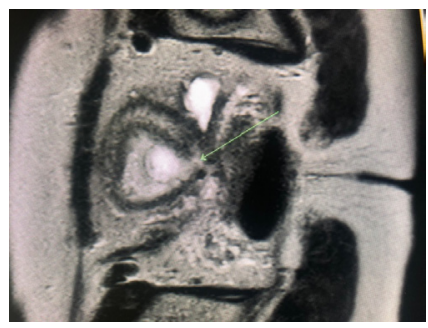

(2)
Pictures 1 and 2 show a thinned (up to $2 \mathrm{~mm}$ ) postoperative scar with a niche of $12 \times 10 \mathrm{~mm}$ in size. In the uterine cavity, there is an embryo $(48 \times 26 \times 47 \mathrm{~mm}$ in size $)$; the chorionic villi are penetrating the postoperative scar.

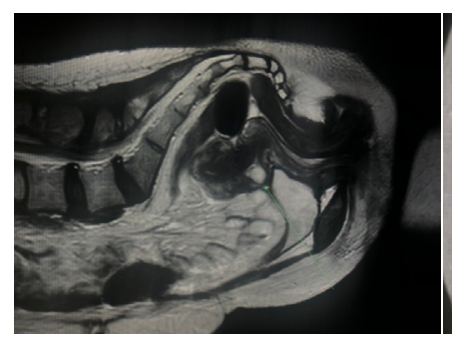

(3)

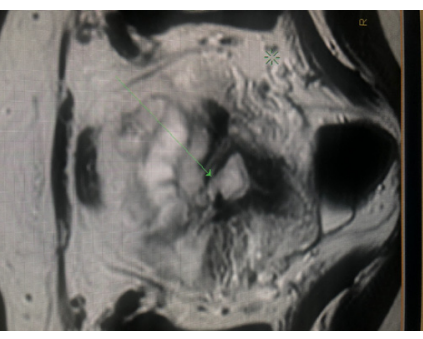

(4)
Pictures 3 and 4 show a thinned (up to $1.8 \mathrm{~mm}$ ) postoperative scar with a niche of $15 \times 12 \mathrm{~mm}$. The MRI revealed an embryo $(23 \times 14 \times 12 \mathrm{~mm}$ in size) lying close to the scar; the boundaries of the scar are blurred.

In Group 1, at the moment of hospitalization, the gestation age was from 6 to 10 weeks. Two patients had planned pregnancies while the others were preparing for medical abortion (5 women), or were hospitalized with uterine bleeding after taking pills for abortion (3 women). Eight $(80 \%)$ patients of Group 1 had 2 uterine scars. Eight patients underwent the emergency caesarian section in the first pregnancy: 1 of them had premature separation of the normally localized placenta, and 7 had inadequate uterine contraction. One of the patients underwent caesarian section at the 33rd week of gestation due to the premature separation of normally localized placenta. The secondary operation was performed routinely for other patients, taking into account the uterine scar from the previous pregnancy. Two $(20 \%)$ patients of Group 1 had one uterine scar: one surgical intervention was caused by severe preeclampsia at the 32 nd week of gestation and one surgical intervention was due to poor labor activity at the 39th week of gestation. The interpregnancy interval was from 6 months to 10 years, with an average of 5 years. In their medical history, 7 (70\%) patients had from 1 to 3 medical abortions.

Nine (90\%) patients of Group 1 underwent metroplasty. In 5 patients, the average blood loss was $100 \mathrm{ml}$. In 4 patients, blood loss was from $1 \mathrm{~L}$ to $1.5 \mathrm{~L}$ : in three women bleeding was associated with taking abortion pills and in one case as the result of early miscarriage caused by uterine infection. All patients underwent vacuum aspiration of the uterus; as the hemorrhage continued, a laparotomy was performed, which confirmed the diagnosis of the PAS disorders. Three of the patients underwent metroplasty; one patient had subtotal hysterectomy as there was endomyometritis caused by uterine infection.

In Group 2, the medical history was as follows: 1 PCS in 1 patient, 2 PCSs in 6 patients $(75 \%)$ and 3 PCSs in 1 patient. Five $(62.5 \%)$ patients had from 1 to 5 previous medical abortions. Two patients applied for medical assistance after an unsuccessful medical abortion induced by taking pills at the period of 5-7 weeks of gestation. An early incomplete abortion was found in 3 patients, and 3 patients had progressive pregnancy after taking abortion pills $(6,7$, and 8 weeks of gestation). All patients underwent laparoscopic metroplasty combined with vacuum aspiration. Total hemorrhage was 100 $\mathrm{ml}$ in 7 patients and $1000 \mathrm{ml}$ in 1 patient at the 8th week of gestation. 
Previous cesarean delivery scars excised during metroplasty represented thin and wide $(1-3 \mathrm{~cm})$ plates of fibrous tissue, granulation tissue, smooth muscle tissue, heterogeneous vessels, and trophoblast. The histological examinations confirmed the presence of trophoblast villi in the uterine scar in all cases; additionally, there were 3 cases of invasion into the myometrium. All patients were discharged in satisfactory condition.

In conclusion, early diagnosis of PAS disorders in patients with previous cesarean delivery scars contributes to adequate operative treatment with minimal blood loss. The risk factors for PAS are the presence of 2 or more cesarean sections, and location of the chorion on the front wall of the uterus, in the scar area or in the area of the internal orifice. In PAS disorders, metroplasty is fertility-preserving surgery with minimal blood loss both by the laparotomic and laparoscopic approaches.

\section{Competing interests} interests.

The authors declare that they have no competing

\section{References}

1. Jauniaux E, Chantraine F, Silver RM, Langhoff-Roos J; FIGO Placenta Accreta Diagnosis and Management Expert Consensus Panel. FIGO consensus guidelines on placenta accreta spectrum disorders: Epidemiology. Int J Gynaecol Obstet. 2018;140(3):265-273. doi: 10.1002/ijgo.12407.

2. Barinova IV, Kondrikov NI, Voloshchuk IN, Chechneva MA, Shchukina NA, Petroukhin VA. [Features of the pathogenesis of the placenta growing in the scar after cesarean section]. Arkhiv Patologii. 2018;(2):18-22. [Article in Russian].

3. Savelyeva GM, Kurtser MA, Breslav IYu, Panina OB, Andreev AI, Barykina OP, Latyshkevich OA. [Invasion of placenta previa in patients with a uterine scar after cesarean section: Clinical and morphological sections]. Akusherstvo i Ginekologiya. 2015;(11):41-45. [Article in Russian].

4. Placenta Praevia and Placenta Accreta: Diagnosis and Management (Green-top Guideline No. 27a). London: Royal
College of Obstetricians \& Gynaecologists; 2011.

5. Tantbirojn P, Crum CP, Parast MM. Pathophysiology of placenta creta: the role of decidua and extravillous trophoblast. Placenta. 2008 Jul;29(7):639-45. doi: 10.1016/j. placenta.2008.04.008.

6. Jauniaux E, Collins S, Burton GJ. Placenta accreta spectrum: pathophysiology and evidence-based anatomy for prenatal ultrasound imaging. Am J Obstet Gynecol. 2018 Jan;218(1):75-87. doi: 10.1016/j.ajog.2017.05.067.

7. Tskhai VB, GlyzinaYuN, Yametov PK, Levanova EA, Lobanova TT, Gritzaeva EA, Chubko MA. Placenta previa and increta into the lower segment myometrium and cervical canal with uterine artery aneurysm in pregnant women with no uterine scar. Akusherstvo i Ginekologiya, 2019;(5):194-199. [Article in Russian].

8. Goh WA, Zalud I. Placenta accreta: diagnosis, management and the molecular biology of the morbidly adherent placenta. J Matern Fetal Neonatal Med. 2016;29(11):1795-800. doi: 10.3109/14767058.2015.1064103.

9. Vinitskiy AA, Shmakov RG. The modern concepts of etiology and pathogenesis placenta accreta and prospects of its prediction by molecular diagnostics. Akusherstvo i Ginekologiya. 2017;(2):5-10. [Article in Russian].

10. Vinitskiy AA, Shmakov RG, Bychenko VG. Current methods for instrumental diagnosis of placenta increta. Akusherstvo i Ginekologiya, 2017;(3):12-17. [Article in Russian].

11. Warshak CR, Eskander R, Hull AD, Scioscia AL, Mattrey RF, Benirschke K, Resnik R. Accuracy of ultrasonography and magnetic resonance imaging in the diagnosis of placenta accreta. Obstet Gynecol. 2006 Sep;108(3 Pt 1):573-81.

12. Riteau AS, Tassin M, Chambon G, Le Vaillant C, de Laveaucoupet J, Quéré MP, et al. Accuracy of ultrasonography and magnetic resonance imaging in the diagnosis of placenta accreta. PLoS One. 2014 Apr 14;9(4):e94866. doi: 10.1371/ journal.pone.0094866. eCollection 2014.

13. Speroff L, Fritz MA. The endocrinology of pregnancy. In: Fritz MA, Speroff L, editors. Clinical Gynecologic Endocrinology and Infertility. 7th edition. Lippincott Williams \& Wilkins, Philadelphia, PA, USA; 2005:259- 315.

14. Ersoy AO, Oztas E, Ozler S, Ersoy E, Erkenekli K, Uygur D, Caglar AT, Danisman N. Can venous ProBNP levels predict placenta accreta? J Matern Fetal Neonatal Med. 2016 Dec;29(24):4020-4. doi: 10.3109/14767058.2016.1152576. 